\title{
Consolidation Parameters of Reconstituted Peat Soil: Oedometer Testing
}

\author{
N.N. Johari ${ }^{1,}$, I. Bakar ${ }^{2, ~ b}$, and M.H.A. Aziz ${ }^{3, c}$ \\ 1, 2, 3 Department of Infrastructure and Geomatic Engineering, \\ Faculty of Civil and Environmental Engineering, \\ Universiti Tun Hussein Onn Malaysia, Batu Pahat, Johor, Malaysia \\ annadiajohari90@gmail.com, bbismail@uthm.edu.my, chanif19590@yahoo.com
}

Keywords: Peat, settlement, reconstituted sample, oedometer consolidation test.

\begin{abstract}
This paper presents the consolidation parameters of reconstituted peat soils with different peat soil particle sizes. The reconstituted peat sample was used to determine the consolidation parameters since the undisturbed samples were difficult to collect. The selected sizes of soil particles passing given sieve sizes have been collected and formed the reconstituted peat samples by preloading with a given pressure. The testing involve was one-dimensional oedometer consolidation test with the load increment method $(5-320 \mathrm{kPa})$. It is important to gather the information about a soil profile, especially on consolidation properties which were important in predicting the settlement of soil. Based on the results, compression index (Cc) and swell index (Cs), the values were increased with the increasing peat particles size.
\end{abstract}

\section{Introduction}

Peat soil is a dark brown soil and a mixture of fragments of fibrous organic materials partly from decomposed plant matter remains and undergoes chemical and physical reactions. Peat can be found throughout the world and Malaysia is included. Malaysia has about $25,000 \mathrm{~km}^{2}$ of peat land and Leete (2006), as cited in [8] has stated about 228,960ha of peat were located in Johor. This type of soil are unsuitable to resist loads and generally unable to perform for most engineering projects in their natural state [5]. Whitlow [13] highlighted that the peat soil has high of compressibility of with range of $0.9-1.5$, high in moisture content (may up to $1000 \%$ ); high organic content $(>75 \%$ ) and high fiber content which poses serious settlement issue. The permeability and bearing capacity of the soil is low and thus unable to withstand heavy loads. The soil will have an excessive settlement and the settlement occurs for a long period of time. For site investigation, the difficulty is based on soil sampling purposes and this due to the behavior of peat soil which is extremely soft and has high moisture content and hence, it requires meticulous work to collect the soil sample in a natural condition. The normal sampling process to obtain undisturbed sample is almost impossible to be conducted. The process of obtaining undisturbed samples using 'block sample' technique was only the other best option to obtain the undisturbed sample. However, the technique is only limited to obtain samples at shallow depth.

Based on Taylor [12], peat particles are made up from decomposed leaves and plant stems. Peat particles might be described as composed of "organics" materials, has porous and may contain internal liquids, highly compressible, flexible and the particles is elongated, laminar or fibrous. Peat soil has divided into three types of peat which are fibric, hemic and sapric. The types of peat can be recognized from the Von Post classification system (H1 to $\mathrm{H} 10)$ and the fiber content in the soil composition. ASTM standards [2] has defined, the organic soil that has organic content more than $75 \%$ is classified as peat and the type of peat can be recognized by the fiber content; fibric peat has more than $67 \%$ of fibers (least decomposed), hemic with $33 \%$ to $67 \%$ (moderately decomposed) and lastly is sapric with $33 \%$ of fiber content which highly decomposed. The different types of peat will influence the consolidation or compressibility of the soil. Kazemian, Huat and Prasad [10]; Sridharan and Nagaraj [11] has highlighted that the more fibrous the peat, the higher the void ratio and water content. In circumstances, the properties of peat greatly depend on the formation of its 
deposits. In consolidation process, peat soil has taken longer time than other types of soils and the compression of peat is much larger. The dominant factors which controlling the compressibility of peat stated by Mesri and Ajlouni [9] is fiber content, natural water content, void ratio, initial permeability, nature arrangement of soil particles, and inter-particles bonding in some of the soils. In addition, the organic materials strongly affected the compressibility of the soil based on the humification. By referring to the types of peat; fibric, hemic and sapric; the compressibility of the fibric is the highest (due to the hollow structures compared to other types) and followed by the hemic and the sapric type of peat [7]. In order to determine the consolidation parameters which can be an indicator for compressibility and settlement of peat, one-dimensional oedometer testing has to be conducted. Hence, this paper covered the determination of consolidation parameters of reconstituted peat soil for different particle sizes by using an oedometer consolidation test with a loading increment method which will be explain in experimental investigation part.

\section{Experimental Investigation}

Peat Sampling For the laboratory testing on the investigation of consolidation parameters, sampling of peat was carried out and collected from a site in Parit Nipah Darat, Batu Pahat, Johor, Malaysia. The samples were excavated to a depth of 0.3 to $1.0 \mathrm{~m}$. The soil was excavated and collected randomly as disturbed peat samples to form reconstituted samples. The disturbed samples were placed and kept in plastic containers with lid to preserve the natural moisture content. Based on the observation, the ground water table has been identified at a depth of $0.3 \mathrm{~m}$ from the ground surface. The color of the soil was brown to dark brown and according to Von Post Scale Classification test; the soil sample was classified through the degree of humification as H6 where the soil sample was moderately decomposed.

Basic Soil Properties of Peat Some basic investigations conducted to determine the basic soil properties. The natural moisture content was high with $495.15 \%$ and the liquid limit was $350 \%$. The values for the initial void ratio, specific gravity and the bulk density of the Parit Nipah peat sample were $8.359,1.359$ and $1.075 \mathrm{~g} / \mathrm{cm}^{3}$ where these values indicated that the soil had a low density and lighter than other soil particles. Based on the void ratio, the soil particles were very porous and make the soil spongy. This may due to the organic content $(75.71 \%)$ and fiber content $(65.37 \%)$ contains in the specimens of peat soil. ASTM standards [2] have stated, the hemic peat has fiber content was in ranges of $33 \%$ to $67 \%$ and the fibric peat has greater than $67 \%$ of fibers while the sapric peat was classified in range less than 33\% of fibers. From this investigation, the peat samples were identified in a group of hemic peat and the statement was supported by observation results using Von Post Classification tested in site field, which soil samples were in H6 as stated before.

Preparation of Reconstituted Peat Reconstituted peat has been used in this study and was prepared in the laboratory by a specified procedure. Reconstitution of peat soil for selected sizes passing were conducted in a few steps; the disturbed samples was sieved (wet sieved) passing selected sieve aperture of $3.35 \mathrm{~mm}, 2.36 \mathrm{~mm}, 1.0 \mathrm{~mm}, 0.425 \mathrm{~mm}$ and $0.300 \mathrm{~mm}$ to remove the larger particles retained. Then, the slurry sample of peat soil particle passing was placed in a reconstitution mould and pressurized with application of $200 \mathrm{kPa}$ by using large strain consolidation equipment. The pressure has been maintained until the excess pore pressure was removed. After reconstitution process, the sample specimens were extruded into a consolidation ring with $75 \mathrm{~mm}$ in diameter and $20 \mathrm{~mm}$ in height for testing purposes.

Experimental procedure: One-Dimensional Oedometer Consolidation Test. One-dimensional oedometer consolidation tests were performed on reconstituted samples with the purpose of the evaluation of the effect on pressure applied and the soil particles sizes in terms of the compressibility of the soil samples. The specimens were prepared as explained before and the 
loadings of each specimen have been performed by the load increment method in the range of 5 $320 \mathrm{kPa}$. Each load was maintained for 24 hours and the data were recorded automatically as prescribed in BS1377 and ASTM D2435 standards. Stages of loading included the loading and unloading stage and each test was repeated for two times. The samples were drained from top and bottom. The testing was conducted in the same laboratory which was in the Research Centre of Soft Soils, Malaysia (RECESS), UTHM.

\section{Results and Discussions}

The results was based on the determination of consolidation parameters in terms of preconsolidation pressures $\left(\mathrm{p}_{\mathrm{c}}\right)$, compression index $(\mathrm{Cc})$, swell index (Cs), Coefficient of consolidation $\left(\mathrm{c}_{\mathrm{v}}\right)$ and coefficient of volume compressibility $\left(\mathrm{m}_{\mathrm{v}}\right)$ which were collected from onedimensional oedometer consolidation testing. The data collected has been analyzed by two curves fitting methods, namely as a logarithm of time or log time method (Casagrande's method) and square root time method (Taylor's method) for determination of $c_{v}$ and $m_{v}$ values while for the $p_{c}$, $\mathrm{Cc}$ and $\mathrm{Cs}$, the values were obtained from the graph void ratio, e against log pressure as shown as in Fig. 1.

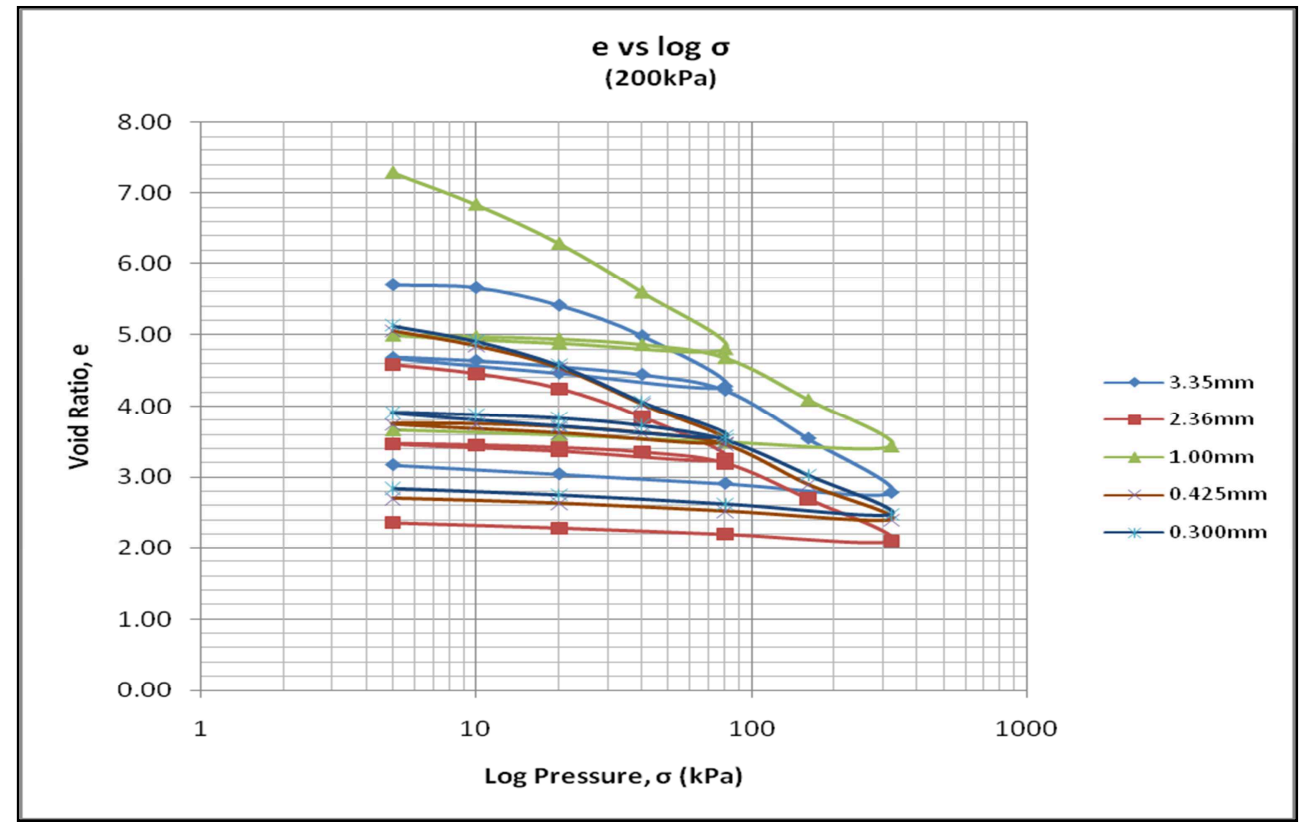

Fig.1 Graphs e against log pressure of reconstituted peat soils.

The $\mathrm{p}_{\mathrm{c}}$ values of reconstituted samples were in the range of 15 to $33 \mathrm{kPa}$. The values were determined from the void ratio against logarithm pressure graph as shown in Fig. 1. Based on Fig. 1, Cc and Cs value of the reconstituted samples were 1.700 to 2.3641 and 0.1434 to 0.2166 respectively and the values were summarized as in Table 1. It shows that, the natural compressibility of peat in Parit Nipah Darat, Batu Pahat was high and it may result from the organic materials and fiber content in the soil. The graph $\mathrm{Cc}$ and $\mathrm{Cs}$ against soil particle sizes (passing) were shown in Fig. 2. The Cc and Cs values increased with the soil particle size increases from 1.579 to 2.3641 and from 0.143 to 0.278 and the $\mathrm{R}^{2}$ value was 0.427 and 0.363 . The values affected with the diameter of soil particles. This clearly shown that, the values of $\mathrm{Cc}$ and $\mathrm{Cs}$ is higher when the diameter of the soil particles is bigger. 


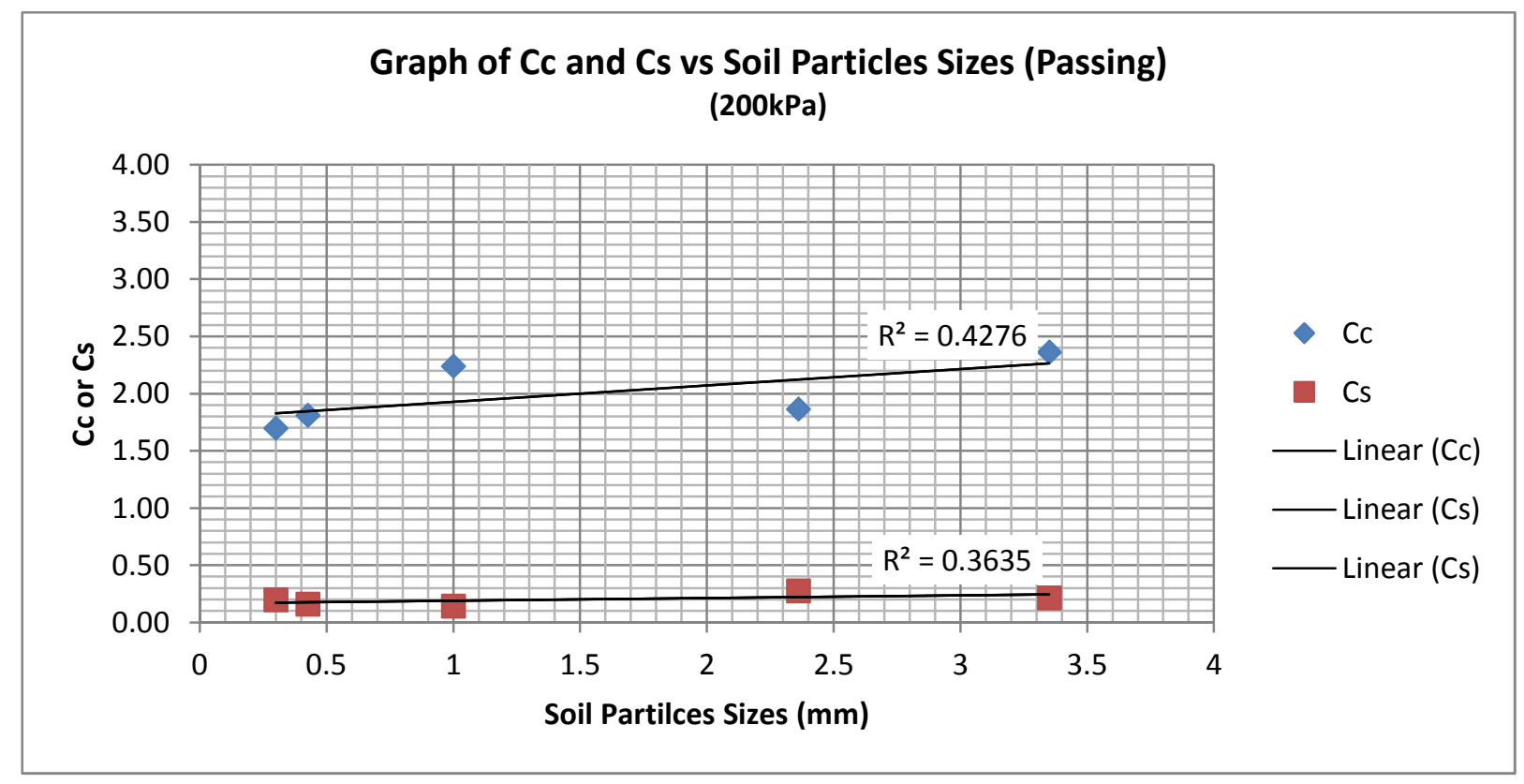

Fig. 2: Graphs of Cc and Cs against soil particles sizes (passing) for reconstituted samples.

Table 1: Summary of Consolidation Parameters of Undisturbed sample and Reconstituted samples

\begin{tabular}{c|cccccc}
\hline \multirow{2}{*}{$\begin{array}{c}\text { Reconstituted } \\
\text { (Passing) }(\mathrm{mm})\end{array}$} & $\begin{array}{c}\text { Initial } \\
\text { Void } \\
\text { Ratio, } \mathrm{e}_{\mathrm{o}}\end{array}$ & $\begin{array}{c}\text { Preconsolidation } \\
\text { Pressure, Pc } \\
(\mathrm{kPa})\end{array}$ & $\begin{array}{c}\text { Compression } \\
\text { Index, Cc }\end{array}$ & $\begin{array}{c}\text { Swell } \\
\text { Index, Cs }\end{array}$ & $\begin{array}{c}\text { Coefficient of } \\
\text { Consolidation, } \mathrm{c}_{\mathrm{v}} \\
\left(\mathrm{m}^{2} / \mathrm{yr}\right)\end{array}$ & $\begin{array}{c}\text { Coefficient of Volume } \\
\text { Compressibility, } \mathrm{m}_{\mathrm{v}} \\
\left(\mathrm{m}^{2} / \mathrm{MN}\right)\end{array}$ \\
\hline 3.35 & 5.7135 & 24 & 2.364 & 0.217 & $13.594-0.064$ & $3.824-0.590$ \\
2.36 & 4.785 & 33 & 1.867 & 0.278 & $35.946-0.977$ & $4.480-0.012$ \\
1.0 & 8.3446 & 15 & 2.242 & 0.143 & $1.666-0.195$ & $25.613-0.577$ \\
0.425 & 5.2524 & 16 & 1.811 & 0.162 & $5.314-0.425$ & $7.096-0.889$ \\
0.300 & 5.271 & 16 & 1.700 & 0.200 & $2.880-0.006$ & $7.257-0.982$ \\
\hline
\end{tabular}

Determination of the coefficient of consolidation, $\mathrm{c}_{\mathrm{v}}$ was based on two curves fitting methods as mentioned before. The values have been calculated from every load increment on the sample and the change in height of the sample over the time. Based on the results, values of $c_{v}$ decreased when the applied load was increased. The coefficient of volume compressibility, $m_{v}$ will affected by $c_{v}$ values. The result of $c_{v}$ and $m_{v}$ are as shown in Table 1 . The $c_{v}$ and $m_{v}$ values were dependent on the void ratios which the values were large when the void ratios were high.

\section{Conclusion}

Based on the results presented in this paper, the consolidation parameters of peat soil were affected by the different soil particles sizes. It was shown that the initial void ratio decreased when the samples composition contains smaller soil particles. Natural void ratio and consolidation behavior of peat had greatly affected by the soil particle size. For the sample contains larger particles, it may contain high fiber content compared to the sample contains smaller particles and thus, the compression of soil was higher as proved by the graph of Cc against soil particle sizes. Hence, these parameters should be highlighted during the investigation of compressibility of peat soil and it indicates that the soil particle distribution in peat gives impact to the compressibility of the soil in order to predict the settlement of soil load were applied. 


\section{Acknowledgement}

The authors wish to give special thanks and acknowledge to the research grant vot no. 1413 for research funding, and Research Centre for Soft Soils (RECESS) UTHM, Geotechnical Laboratory FKAAS, and staffs UTHM for providing the equipments and giving support during carrying out this research.

\section{References}

[1] J. P. Andriesse, Nature and Management of Tropical Peat Soils. Food and Agriculture Organization of the United Nations (FOA) (1988).

[2] ASTM Standards.Construction. Soil and Rock (I): D420-D5611. West Conshohocken, PA, ASTM Standards Volume 04.08. (2007).

[3] Y. Duraisamy, B.B. Huat, \& A.A. Aziz, Engineering Properties and Compressibility Behavior of Tropical Peat Soil. American Journal of Applied Sciences, 4 (10), (2007) p.768-773.

[4] Y. Duraisamy, B.B. Huat, R. Muniandy, \& A.A. Aziz, Compressibility behavior of fibrous peat reinforced with cements columns. International conference on construction and building technology (ICCBT), (2008) (p. 93-110).

[5] N.Gofar, \& Y. Sutejo, Long Term Compression Behavior of Fibrous Peat. Malaysian Journal of Civil Engineering, 19 (2), (2007) 104-116.

[6] R. Hashim, \& S. Islam,. Engineering Properties of Peat Soils in Peninsular, Malaysia. Journal Applied Science (2008).

[7] B.B. Huat, A.Prasad, A. Asadi, \& S. Kazemian,. Geotechnics of Organic Soils and Peat. London: CRC Press (2014).

[8] S. Kazemian, , B. B. Huat, A. Prasad, \& M. Barghchi,. A State of Art Review of Peat: Geotechnical Engineering Perspective. International Journal of the Physical Sciences, 6 (8), (2011) p.1974-1981.

[9] G. Mesri, , and M. Ajlouni,. Engineering Properties of Fibrous Peat. Journal of Geotechnical and Geoenvironmental Engineering (2007, July).

[10] S. Kazemian, B. B. K. Huat, A. Prasad,. A State of Review of Peat: Geotechnical Engineering Perspective. International Journal of Physical Sciences (2011).

[11] A Sridharan. and H.B Nagaraj. Geotechnical Testing Journal. Coefficient of Consolidation and Its Correlation with Index Properties of Remolded Soils. (2012) (Volume 27, No.5).

[12] H. F. Taylor. Peat behavior-Some conceptual mechanisms and challenges.

[13] R. Whitlow. Basic Soil Mechanics (Fourth Ed.). Harlow, England: Pearson Education Ltd (2001). 